\title{
La delimitación de funciones entre el personal funcionario y laboral: Especial referencia a la reordenación del sector público de Andalucía'
}

\author{
Javier E. Quesada Lumbreras \\ Profesor de Derecho Administrativo. Universidad de Granada \\ jaque@ugr.esl
}

Recibido: 31 de julio de 2012 Aceptado: 24 de mayo de 2013

Resumen

El objeto de este trabajo es analizar el proceso de reordenación del sector público de Andalucía. En este contexto, intentaremos dejar sentados unos lineamientos básicos sobre las funciones que deben asumir estos trabajadores del sector público. $Y$ es que, en efecto, contamos con unos criterios legales, aunque no sean todo lo clarificadores que desearíamos, pero que han de ser tenidos en cuenta también aquí, en el presente caso que nos ocupa.

\section{The delimitation of functions among the statutory permanent post and non statutory permanent post: special reference to the reordering of the public sector of Andalusia}

\begin{abstract}
The subject of this paper is to analyse the process of reorganizing the public sector in Andalusia. In this context, try to leave sit a few basic guidelines on the functions they must assume these public sector workers. In fact, we have some legal standards, whether or not clarifying what we wish, but must be taken into account here, in this particular case.
\end{abstract}

Key words

Public Administration, Human Resources, Public functions.

1 El presente trabajo de investigación se ha realizado en el marco de los Proyectos "Aspectos jurídicos de la economía urbana para el desarrollo sostenible" (DER2010-18321) y "Régimen jurídico de la economía urbana para el desarrollo sosteible de Andalucía" (P10-SEJ-5826). 


\section{INTRODUCCIÓN: LA REORDENACIÓN DEL SECTOR PÚBLICO DE ANDALUCÍA}

\section{La problemática planteada}

Llama la atención, una vez más, las declaraciones del Tribunal Superior de Justicia de Andalucía (TSJA), en su Sentencia de 25 de febrero de 2011 por la que se declara la nulidad de pleno derecho del Decreto 324/2009 por el que se aprueba el Estatuto de la Agencia Tributaria de Andalucía, cuando afirma que: "Efectivamente, la fuga del Derecho Administrativo, tan criticada doctrinalmente, se vienen produciendo en las últimas décadas de manera silenciosa, y muchas veces oculta en normas auto-organizativas, que por los motivos ya indicados no se someten a los filtros previos a los que se sujetan otras normas ejecutivas de menos trascendencia para el desarrollo y funcionamiento de la vía administrativa".

Y añade que: "La doctrina científica e instituciones, como el Defensor del Pueblo, insisten en que la mayor eficacia y agilidad en la gestión de los servicios públicos, a través de formas jurídico privadas, no puede suponer un quebranto en las garantías de los derechos de los ciudadanos. El riesgo de merma de esos derechos se plasma con la cada vez mayor asunción por parte de entes públicos instrumentales, bajo formas privadas, de actuaciones y servicios públicos sin el pleno control de las normas administrativas y de la jurisdicción contenciosa-administrativa, que precisamente tiene por función esencial revisar la actuación de la Administración. No puede olvidarse que tales entes instrumentales siguen teniendo, con independencia de su forma jurídica, naturaleza de poderes públicos y por ello están sometidos a los principios constitucionales a los que se debe escrupulosamente ajustar la Administración: artículos 9.3, 53.1, 103.1 ó 105 c) de la Constitución, entre otros"2.

Así, como expresó el Defensor del Pueblo Andaluz en su Informe al Parlamento de Andalucía sobre la gestión realizada durante 2010, presentado el 29 de marzo de 2011: "Ello no impide para que sobre esta misma cuestión, referida a los modelos de organización de la Administración Pública, el Defensor del Pueblo Andaluz haya mantenido una continua intervención en numerosas quejas o con motivo de consideraciones que se han expresado en los Informes Anuales presentados al Parlamento".

Destacamos, como añade, "los posicionamientos mantenidos por esta Institución. Así en el pleno del Parlamento celebrado el 27 de Octubre de 1999, expresaba el Defensor del Pueblo Andaluz con motivo del debate del Informe Anual de 1998: “(...)

2 Esta Sentencia tiene su origen en la impugnación presentada por el Sindicato Andaluz de Funcionarios en la que, además de denunciar la falta de negociación previa durante la elaboración de dichos estatutos, expuso la necesidad de que la Agencia Tributaria Andaluza se constituyera como una agencia administrativa y no de régimen especial, dado que era incompatible este tipo de agencias con la reserva que con carácter exclusivo hace para el funcionario el artículo 9.2 del EBEP. Y que llevó a concluir al TSJA que: "En la elaboración del Decreto impugnado hubiera sido de todo punto útil que los distintos sindicatos, que representan los intereses de los funcionarios públicos y en general del personal al servicio de la Administración y las Corporaciones profesionales hubieran podido, al menos, emitir su parecer

144 o juicio sobre la misma, formulando alegaciones, dado el conocimiento e interés que tienen en la actividad ambiental de la Administración Pública y en el posible desapoderamiento de atribuciones de ésta". 
Esta institución es consciente de la necesidad de articular formas flexibles de administrar que permitan disponer de instrumentos ágiles y eficaces de gestión administrativa. Ello, sin embargo, no debe ser incompatible con la observancia de estos principios y normas que establecen los límites y cautelas para un funcionamiento objetivo y garantizador de los derechos e intereses de todos los ciudadanos; es decir, con independencia de la figura que se utilice y de los medios que se empleen, no dejamos de estar en presencia de genuinas actividades de la Administración pública, y, por lo tanto, sometidas a un régimen jurídico público y garantista hacia el ciudadano. En ese sentido, me permito sugerir a los señores Diputados y señoras Diputadas que, en la próxima reforma que se pudiera acometer de la ley reguladora de la organización y administración de la Comunidad Autónoma andaluza, que data de 1983, sería deseable y muy clarificador abordar esta problemática, de manera que se identificaran las funciones irreductiblemente públicas que no pueden ser prestadas bajo fórmulas de derecho privado, a la vez que quedara perfectamente determinado el régimen jurídico aplicable a estas empresas participadas por la Administración en los distintos aspectos de su actividad" (DSPA 140/V Legislatura, pág. 8.236)"

Y es que, en efecto, esta problemática se viene produciendo desde años atrás e incluso, en algunos casos, ha sido frenada por los propios órganos jurisdiccionales. Así podemos citar, como ejemplos de estos pronunciamientos judiciales, la Sentencia de 25 de mayo de 2009 del TSJA por la que se declaraba también nula la Orden de 4 de septiembre de 2008 del Servicio Andaluz de Empleo por el que se formalizaba acuerdo de encomienda con la Fundación Andaluza Fondo Formación y Empleo: "La anulación de actividades o de participantes sólo pueden ser entendidas como ejercicio de potestades administrativas. Y si se tiene en cuenta que el personal de la fundación no forma parte de lo que llamamos ya empleados públicos, es claro que se vulnera el precepto antes citado (art. 9.2) de la Ley 7/2007. En todo caso, se está encomendando el ejercicio de potestades administrativas para unas tareas que exceden del contenido legal que esta institución puede tener". Y añade que: "En fin, la suficiencia o no del personal del servicio andaluz de empleo no puede ser motivo para encomendar una gestión si ello se hace a costa de sacrificar los principios esenciales de esta institución".

En esta misma línea, también podemos citar el Auto del TSJA de 19 de octubre de 2009, que acordaba, como medida cautelar, la suspensión de la Resolución de 27 de febrero de 2009 por la que se realiza una encomienda de gestión a SADESI (Sociedad Mercantil adscrita a la Consejería de Innovación, Ciencia y Empresa) para la operación y soporte de Sistemas de Gestión empresarial implantado en la Agencia Andaluza de Cooperación Internacional para el Desarrollo, y en la que se atribuía el ejercicio de potestades públicas reservadas a funcionarios al personal de la sociedad mercantil mencionada 3 .

3 Como concluye el citado Auto: “Dentro de las limitaciones que todo juicio cautelar tiene y por supuesto sin prejuzgar la Resolución de Encomienda, consideramos como la parte apelante que concurren los presupuestos para la adopción de la medida por las siguientes consideraciones: 
Y del mismo modo, el Auto de 7 de junio de 2010 del Juzgado de lo ContenciosoAdministrativo $\mathrm{N}^{\circ} 6$ de Sevilla, que acuerda también la suspensión cautelar de la Resolución de 13 de noviembre de 2009 del Servicio Andaluz de Empleo por la que se formaliza acuerdo de encomienda de gestión para la explotación de datos derivados de la Gestión de la Formación de Oferta dirigida prioritariamente a trabajadores ocupados, encargada por el Servicio Andaluz de Empleo a la Fundación Andaluza Fondo Formación y Empleo (FAFFE). Esta suspensión, dicho sea de paso, ha sido reafirmada recientemente por el TSJA en su Sentencia de 21 de marzo de 2011.

O, por poner un último ejemplo, el Auto de 22 de junio de 2010 del TSJA por el que se adopta la medida cautelar consistente en la suspensión de la Orden de 8 de septiembre de 2009, por la que se encomienda a la Agencia de Innovación y Desarrollo de Andalucía la realización de las actuaciones materiales precisas de la expropiación forzosa de los terrenos necesarios para la ejecución de la propuesta de actuación de implantación del Centro Tecnológico Avanzado de Energías Renovables en el término municipal de Tabernas (Almería).

\section{La respuesta de la Junta de Andalucía}

Paralelamente, en este escenario, la Junta de Andalucía con la finalidad de acomodar el sector público andaluz a las nuevas circunstancias económicas y financieras, ha llevado a cabo una serie de medidas que tenían como objetivo básico, según establece en la Exposición de Motivos de la Ley 1/2011, de 17 de febrero, de reordenación del sector público de Andalucía (en adelante, Ley 1/2011): “mejorar la gestión, la calidad en la prestación de los distintos servicios públicos y el desarrollo de las funciones que les son propias a las Consejerías, teniendo en consideración los medios personales y materiales disponibles y desarrollando el máximo posible de las potestades administrativas con sus propios recursos".

Dentro de aquellas medidas se encontraba por un lado, el Decreto-Ley 5/2010, de 27 de julio, por el que se aprueban medidas urgentes en materia de reordenación del sector público. Y, por otro, el Decreto-ley 6/2010, de 23 de noviembre, que complementa al anterior y concreta los procedimientos de integración del personal funcio-

a) Si hasta la fecha de la Resolución todas las funciones encomendadas eran realizadas por el personal y funcionarios de la Agencia adscrita a la Consejería de Presidencia, la adopción de la medida no perturbaría el interés general y sin embargo, la no adopción podría hacer perder la finalidad legítima al recurso, pues si los trabajadores de una mercantil ejercen potestades públicas en la ejecución de la encomienda la situación sería difícilmente reversible.

b) En la ponderación de intereses en conflicto, el interés general alegado por la Administración y plasmado en la nota informativa, no se ve perturbado porque dichas funciones puedan realizarse como hasta ahora por los numerosos funcionarios que tiene la Administración a quien incumbe la planificación y racionalización de sus recursos humanos, sin necesidad de aumentar el gasto.

c) Por último, la apariencia de buen derecho, tampoco es desdeñable, porque esta Sala ya ha estimado el recurso 597/2008, del mismo Sindicato contra otra encomienda de gestión al entender que contenía el ejercicio de potestades públicas reservadas a los funcionarios". 
nario y laboral que pudiera verse afectado por la aplicación de las medidas contempladas en el primero de los decretos-leyes mencionados ${ }^{4}$.

En este contexto, cabe destacar también la modificación de diversos preceptos de la Ley 9/2007, de 22 de octubre, de la Administración de la Junta de Andalucía, especialmente los referidos al personal funcionario y laboral que se integre en las nuevas agencias públicas empresariales creadas por la Ley $1 / 2011$.

De esta forma, junto a la regulación ya conocida de las sociedades mercantiles y fundaciones del sector público, se viene ahora a realizar algunas modificaciones en el otro brazo instrumental, en este caso de carácter público, de la Administración andaluza, a saber: las agencias administrativas, las agencias públicas empresariales y las agencias de régimen especial que, junto a las primeras, constituyen todo el extenso aparato burocrático de las entidades instrumentales de la Administración de la Junta de Andalucía y que, dicho sea de paso también, son propiamente Administración Pública a diferencia de las anteriores.

Sin embargo, no es nuestro propósito volver analizar globalmente este proceso de descentralización funcional en el contexto actual55. Sí nos preocupa, más concreta-

4 Según establece la Exposición de Motivos de la Ley 1/2011, que reproduce e integra todas estas medidas: “..en virtud del diálogo social permanente, el día 18 de noviembre de 2010 se alcanzaron una serie de acuerdos en la Mesa General de Negociación del Empleado Público de la Administración de la Junta de Andalucía, que modificaron determinados aspectos del Decreto-Ley 5/2010, de 27 de julio, a fin de concretar los procedimientos de integración del personal funcionario y laboral que pudiera verse afectado por la aplicación de las medidas contempladas en la citada norma".

Las cuestiones más importantes de dichos acuerdos están relacionadas, según expone, “con las garantías de salvaguarda de los derechos de los empleados públicos, reforzando la voluntariedad del proceso de integración. Asimismo, queda garantizada la aplicación del Acuerdo de Condiciones de Trabajo del Personal Funcionario y la aplicación del Convenio Colectivo de la Administración de la Junta de Andalucía al personal laboral de dicha Administración hasta que, en su caso, exista un nuevo convenio colectivo. De igual forma, se indica que se mantiene la condición de personal funcionario o laboral, con independencia de su integración en alguna de las nuevas agencias".

También, añade, "queda reforzada la garantía de los principios de igualdad, mérito, capacidad y publicidad para el acceso a la condición de personal funcionario o laboral de la Administración General de la Junta de Andalucía. De este modo, se establece expresamente que no existirá ningún procedimiento de acceso a dicha condición distinto al establecido para la ciudadanía en general, para el personal laboral que se integra en las nuevas agencias, procedente de entidades instrumentales que se extinguen o se transforman".

5 Si nos preocupa ahora, más concretamente, uno de los fenómenos que se puede esconder detrás de todo este proceso: “... huir de las normas de selección de funcionarios o de contratación de personal por la Administración, que persigue contratar personal laboral eventual cuando realmente hay una tarea estable que simplemente se descompone artificialmente en una sucesión de encargos temporales, que se busca realizar con personal laboral lo que legalmente está reservado a funcionarios públicos. Porque todo esto, además, produce el efecto de que tareas puramente administrativas propias de las Consejerías se realizan a través de sociedades anónimas por personal no funcionario, sin ninguna garantía de independencia. No se llega formalmente a encomendar a estas sociedades mercantiles públicas y a su personal laboral temporal el ejercicio de potestades administrativas que impliquen autoridad. Pero, aun así, se está muy cerca de ello: no se les encomienda propiamente la inspección o la de dar órdenes, pero sí actividades de colaboración con la inspección que, al final, acaban siendo las mismas de los inspectores propiamente dichos; no se les atribuye la resolución de expedientes y la de recursos administrativos, pero sí la de las actividades materiales y técnicas necesarias para la instrucción, lo que, en el fondo, supone que los trami- 
mente, si analizamos detenidamente la Ley $1 / 2011$, el régimen jurídico y el ejercicio de potestades administrativas de las agencias públicas empresariales que se establece en la nueva redacción de los arts. 68 y 69 de la Ley 9/2007 de la Administración de la Junta de Andalucía, que pueden ser de dos tipos:

a) Aquellas que tienen por objeto principal la producción, en régimen de libre mercado, de bienes y servicios de interés público destinados al consumo individual o colectivo mediante contraprestación.

b) Aquellas que tienen por objeto, en ejecución de competencias propias o de programas específicos de una o varias Consejerías, y en el marco de la planificación y dirección de estas, la realización de actividades de promoción pública, prestacionales, de gestión de servicios o de producción de bienes de interés público, sean o no susceptibles de contraprestación, sin actuar en régimen de libre mercado ${ }^{6}$.

Partiendo de este esquema, se establece que el régimen jurídico de las primeras será con carácter general el Derecho privado "excepto en las cuestiones relacionadas con la formación de la voluntad de sus órganos y con el ejercicio de las potestades administrativas que tengan atribuidas y en los aspectos específicamente regulados en esta Ley, en sus estatutos, en la Ley General de la Hacienda Pública de la Junta de Andalucía y demás disposiciones de general aplicación”.

Por su parte, el segundo tipo de agencias se regirán por el Derecho Administrativo en las cuestiones que establece la excepción del primer tipo de agencias. Para el resto de aspectos, se regirán por el Derecho Administrativo o por el Derecho Privado según su "particular gestión empresarial así lo requiera".

Ahora bien, como señala la normativa andaluza, estas agencias públicas empresariales ejercerán únicamente "las potestades administrativas que expresamente se les atribuyan y sólo pueden ser ejercidas por aquellos órganos a los que en los estatutos se les asigne expresamente esta facultad". Y añade que "los órganos de las agencias públicas empresariales no son asimilables en cuanto a su rango administrativo al de los órganos de la Administración de la Junta de Andalucía, salvo las excepciones que, a determinados efectos, se fijen, en cada caso, en sus estatutos".

tan en su totalidad...Así, incluso cuando con ello no se vulneran directamente todas las normas sobre procedimiento administrativo y sobre función pública, se consigue que no sirvan de nada pues todas las garantías que comportan para el interés público y para el de los ciudadanos afectados quedan arruinadas" (Rebollo Puig (2003): 392-393).

6 Conforme a la nueva redacción del art. 68.2 de la Ley 9/2007: “Las agencias públicas empresariales se adscriben a una o varias Consejerías. Excepcionalmente pueden adscribirse a una agencia cuyo objeto además consista en la coordinación de varias de ellas. Asimismo, se podrán aplicar técnicas de 148 coordinación funcional entre varias agencias públicas empresariales que compartan la misma adscripción orgánica, a través de órganos o unidades horizontales". 
Y deja bien claro que en el caso de que se trate de funciones que impliquen la participación directa o indirecta en el ejercicio de las potestades públicas o en la salvaguarda de los intereses generales que deban corresponder exclusivamente a personal funcionario, podrá "llevarlas a cabo, bajo la dirección funcional de la agencia pública empresarial, el personal funcionario perteneciente a la Consejería o la agencia administrativa a la que esté adscrita"”.

Pero la cosa no acaba ahí. Por lo que respecta a las agencias de régimen especial, esto es, aquellas entidades públicas a las que se atribuye, en ejecución de programas específicos de la actividad de una Consejería, la realización de actividades de promoción, prestacionales, de gestión de servicios públicos y otras actividades administrativas, siempre que se les asignen funciones que impliquen ejercicio de autoridad que requieran especialidades en su régimen jurídico. Se rigen por el Derecho Administrativo, sin perjuicio de la aplicación del Derecho Privado "en aquellos ámbitos en que su particular gestión así lo requiera”. Ahora bien, en las cuestiones de la excepción del primer tipo de agencias públicas empresariales, las mismas que las del segundo tipo de éstas, se regirán en todo caso por el Derecho Administrativo (nueva redacción del art. 71.2 de la Ley $9 / 2007)^{8}$.

Podríamos decir, de entrada, que la nueva Ley andaluza no nos inspira mucha claridad y certidumbre jurídica de la lectura de sus preceptos. Especialmente para aclararnos en qué casos se aplica el Derecho Administrativo y en cuáles otros se aplica el Derecho Privado. Pero sigamos un poco más, bajemos al plano de la aplicabilidad de las normas. Lo que está claro es que todo esto este entramado jurídico lo tienen que trasladar a nuestra realidad cotidiana personas físicas, los recursos humanos de nuestras organizaciones públicas. Hasta ahí lo tenemos claro. ¿Y qué dice la norma andaluza al respecto?, ¿serán funcionarios?, ¿serán personal laboral?. Veamos si en estos aspectos las cosas son más sencillas.

7 A tal fin, como señala la nueva redacción del art. 69.3 de la Ley 9/2007, "se configurarán en la relación de puestos de trabajo correspondiente las unidades administrativas precisas, que dependerán funcionalmente de la agencia pública empresarial".

La dependencia de este personal, sigue diciendo, "supondrá su integración funcional en la estructura de la agencia, con sujeción a las instrucciones y órdenes de servicio de los órganos directivos de la misma, quienes ejercerán las potestades que a tal efecto establece la normativa general. El decreto por el que se aprueben los estatutos de la agencia contendrá las prescripciones necesarias para concretar el régimen de dependencia funcional, el horario de trabajo y las retribuciones en concepto de evaluación por desempeño y las relativas al sistema de recursos administrativos que procedan contra los actos que se dicten en ejercicio de las potestades administrativas atribuidas a la agencia".

8 Es decir, para no marear más al lector, las cuestiones relacionadas con la formación de la voluntad de sus órganos y con el ejercicio de las potestades administrativas que tengan atribuidas y en los aspectos específicamente regulados en esta Ley, en sus estatutos, en la Ley General de la Hacienda Pública de la Junta de Andalucía y demás disposiciones de general aplicación.

Respecto a las agencias administrativas, la única modificación al respecto se establece en la nueva redacción del artículo 65. 3 de la Ley 9/2007, y queda redactado de la siguiente forma: "3. Las agencias administrativas se adscriben a una Consejería, a la que corresponde la dirección estratégica, la evaluación y el control de los resultados de su actividad en los términos previstos en el artículo 63 de esta Ley. Excepcionalmente pueden adscribirse a otra agencia administrativa cuyo objeto consista en la coordinación de varias de ellas". 
Pues bien. Para que no haya lugar a la confusión, la norma nos aclara que el personal de las agencias públicas empresariales "se rige en todo caso por el Derecho Laboral, así como por lo que le sea de aplicación el Estatuto Básico del Empleado Público" (nueva redacción del art. 70.1 de la Ley 9/2007).

Por su parte, el personal de las agencias de régimen especial "podrá” ser funcionario. $Y$, lógicamente, se regirá por la normativa aplicable en materia de función pública. Pero en este tipo de agencias también habrá, como no podía ser de otra forma, personal sujeto a Derecho Laboral. Aquí ya no sabemos si será de aplicación el EBEP pues el nuevo art. 74.1 de la Ley 9/2007 guarda silencio al respecto. Eso sí, como nos señala en el inciso final del precepto, "las funciones que impliquen ejercicio de autoridad serán desempeñadas por personal funcionario".

Y si ya tenemos "claro" que funciones corresponden a unos y otros, vamos a ver cómo distribuimos nuestros recursos humanos. Para eso tenemos que pasar unas cuantas páginas de la nueva Ley andaluza, después de todos los preceptos referidos a la creación y adaptación de las nuevas agencias y otras medidas varias, hasta llegar a la Disposición adicional cuarta denominada "Régimen de integración de personal”.

Nos habla de un protocolo que adoptará la Consejería competente en materia de Administración Pública, para aquellos casos en que se produzca "la supresión de centros directivos de Consejerías o la extinción de entidades instrumentales públicas o privadas en las que sea mayoritaria la representación y la participación directa o indirecta de la Administración de la Junta de Andalucía y sus agencias”. Sólo en estos casos y no en otros, la integración del personal en las agencias públicas empresariales o de régimen especial que asuman "el objeto y fines de aquellas" se realizará de acuerdo a unas reglas "muy sencillas"

9 Por su parte, como señala el art. 65.2 de la Ley 9/2007 que no ha sido modificado, el personal al servicio de las agencias administrativas "será funcionario, laboral o, en su caso, estatutario, en los mismos términos que los establecidos para la Administración de la Junta de Andalucía. No obstante, la ley de creación podrá establecer excepcionalmente peculiaridades del régimen de personal de la agencia en las materias de oferta de empleo, sistemas de acceso, adscripción y provisión de puestos y régimen de movilidad de su personal".

10 En este contexto, cabe señalar entre esas medidas varias, la creación y/o adaptación a la configuración jurídica de agencia establecida en el Capítulo II de la Ley 1/2011 denominado “Medidas sectoriales de organización”, a saber: Agencia Andaluza del Conocimiento, Agencia de Obra Pública, el Servicio Andaluz de Empleo, Agencia Pública Empresarial Sanitaria Costa del Sol, Agencia de Gestión Agraria y Pesquera, Agencia de Servicios Sociales y Dependencia de Andalucía, Agencia Andaluza de Instituciones Culturales, y, Agencia del Medio Ambiente y Agua de Andalucía.

Asimismo, como establece su Disposición adicional primera, son también agencias públicas empresariales la Agencia Andaluza de Cooperación Internacional para el Desarrollo y el Instituto Andaluz del Patrimonio Histórico.

11 Dice así: «a) Al personal funcionario que se integre orgánicamente en una agencia de régimen especial o se adscriba funcionalmente a una agencia pública empresarial le será de aplicación el Acuerdo de Condiciones de Trabajo del Personal Funcionario de la Junta de Andalucía. La integración del personal funcionario en una agencia pública empresarial será voluntaria. El tipo de contrato y las condiciones de este personal se negociarán con las organizaciones sindicales más representativas. El 
Después de toda estas reglas de integración de personal, seguimos con la senda "didáctica" de la nueva Ley, tal y como nos anunciaba en su Exposición de Motivos, y en su Disposición adicional quinta nos explica ahora qué es el personal directivo de las agencias. Lo que no ha hecho respecto al personal funcionario o laboral. Dice así: “El personal directivo de las agencias es el que ocupa los puestos de trabajo determinados como tales en los estatutos de las mismas, en atención a

personal funcionario que se integre como laboral quedará en sus Cuerpos en la situación administrativa de excedencia voluntaria por prestación de servicios en el sector público andaluz. En caso contrario permanecerá en servicio activo. Al personal funcionario que se integre en una agencia pública empresarial como personal laboral se le considerará como mérito el trabajo desarrollado en la misma cuando participe en convocatorias de concursos de méritos para la provisión de puestos de trabajo en la Administración General de la Junta de Andalucía. A dicho personal se le reconocerá por la agencia de destino el tiempo de servicios prestados en la Administración a efectos de la retribución que le corresponda por antigüedad.

Asimismo, cuando reingrese al servicio activo, el tiempo de permanencia en la agencia se le computará a efectos de reconocimiento de trienios y, en su caso, se le considerará en su carrera profesional.

b) El personal laboral procedente de las entidades instrumentales suprimidas se integrará en la nueva entidad resultante de acuerdo con las normas reguladoras de la sucesión de empresas, en las condiciones que establezca el citado protocolo de integración, y tendrá la consideración de personal laboral de la agencia pública empresarial o de la agencia de régimen especial. El acceso, en su caso, de este personal a la condición de personal funcionario o laboral de la Administración General de la Junta de Andalucía solo podrá efectuarse mediante la participación en las correspondientes pruebas selectivas de acceso libre convocadas en ejecución de las ofertas de empleo público.

c) La integración del personal laboral de la Administración General de la Junta de Andalucía en una agencia pública empresarial será voluntaria. Este personal mantendrá su condición de personal laboral de dicha Administración, siéndole de aplicación el Convenio Colectivo del Personal Laboral de la Administración de la Junta de Andalucía hasta que exista un nuevo convenio colectivo. En dicho momento pasará a la situación del tipo de excedencia que determine el convenio colectivo de procedencia. Al personal laboral procedente de la Administración General de la Junta de Andalucía que se integre en una agencia pública empresarial se le valorará como experiencia laboral el trabajo desarrollado en la misma cuando participe en convocatorias de concursos de traslados para la provisión de puestos de trabajo o promoción interna en la Administración General de la Junta de Andalucía. A dicho personal se le reconocerá por la agencia de destino el tiempo de servicios prestados en la Administración a efectos de la retribución que le corresponda por antigüedad. Asimismo, cuando reingrese al servicio activo en la Administración General de la Junta de Andalucía, el tiempo de permanencia en la agencia se le computará a efectos de reconocimiento de antigüedad y, en su caso, se le considerará en su carrera profesional.

d) El personal laboral de las agencias de régimen especial procedente de la Administración General de la Junta de Andalucía se integra orgánicamente, manteniendo su condición de personal laboral de dicha Administración, siéndole de aplicación el Convenio Colectivo del Personal Laboral de la Administración de la Junta de Andalucía.

e) Los convenios colectivos, así como los acuerdos derivados de la interpretación de los mismos, aplicables a las entidades extinguidas o transformadas y a la Administración General de la Junta de Andalucía seguirán rigiendo los derechos y obligaciones del personal laboral procedente de dichas entidades o de la citada Administración, en tanto se apruebe un nuevo convenio aplicable al mismo, sin perjuicio de lo establecido en la letra d de este apartado.

f) La masa salarial del personal laboral al servicio de la nueva entidad no podrá superar, como consecuencia de la reordenación regulada por esta Ley, la del personal de las entidades que se extingan o se transformen.

g) El referido protocolo de integración se aprobará previa consulta y negociación con los órganos de representación del personal y se someterá a informe de los órganos correspondientes de la Consejería competente en materia de Hacienda.

2. Una vez extinguida la Agencia Andaluza del Agua, el personal funcionario y laboral que presta servicios en la misma se integrará en la estructura de la Consejería de Medio Ambiente». 
la especial responsabilidad, competencia técnica y relevancia de las tareas a ellos asignadas $^{12}$.

Finalmente, y si quizás no ha quedado lo suficientemente claro a lo largo del articulado de la nueva Ley andaluza, nos señala que "el ejercicio de las funciones que impliquen la participación directa o indirecta en el ejercicio de las potestades públicas o en la salvaguardia de los intereses generales corresponde exclusivamente a los funcionarios públicos, en los términos establecidos en la legislación en materia de función pública" (Disposición adicional sexta, Ley 1/2011). Y que todo este proceso, la selección y acceso del personal de los entes instrumentales de la Administración de la Junta de Andalucía, se efectuará mediante "convocatoria pública en medios oficiales y con sujeción a los principios constitucionales de igualdad, mérito y capacidad" (Disposición adicional séptima, Ley $1 / 2011)^{13}$.

Por nuestra parte, estamos bastante preocupados de cómo se pueda articular este proceso de reordenación del sector público andaluz. Por mucho que sus legisladores nos quieran "agasajar" con este nutrido articulado cuya claridad y certidumbre jurídica brilla por su ausencia. ¿Cómo va a "digerir" todo esto los operadores jurídicos?, ¿qué les depara a los empleados públicos andaluces implicados?, ¿y qué pensar de los destinatarios finales de la norma?, nuestros ciudadanos.

La verdad es que no es fácil de "digerir" este compendio normativo. Hay muchas cosas que discutir. Pero nosotros, al menos, queremos colaborar en la ardua tarea a la que se va a enfrentar los operadores jurídicos. Por ello, consideramos imprescindible dejar sentado unos lineamientos básicos sobre las funciones que deben asumir estos trabajadores del sector público, distinguiendo qué puestos de trabajo han de ser desempeñados en todo caso por funcionarios públicos y cuáles otros puedan ser asumidos por personal laboral. $Y$ es que, en efecto, contamos con unos criterios legales, aunque no sean todo lo clarificadores que desearíamos, pero que han de ser tenidos en cuenta también aquí, en el presente caso que nos ocupa.

12 Téngase en cuenta también, como establece los apartados 2 y 3 de esta Disposición, que:. "Su designación atenderá a principios de mérito y capacidad y a criterios de idoneidad, y se llevará a cabo mediante procedimientos que garanticen la publicidad y concurrencia. Los puestos de trabajo que tengan asignadas tareas de dirección que estén relacionadas con el ejercicio de potestades públicas serán desempeñados, en todo caso, por personal directivo que tenga la condición de funcionario de carrera o por quienes sean nombrados por el Consejo de Gobierno como gerentes o jefes de personal de las agencias".

Y que, en consecuencia, su régimen jurídico será el previsto "en el artículo 13 de la Ley 7/2007, de 12 de abril, del Estatuto Básico del Empleado Público, y en la normativa de desarrollo dictada por la Comunidad Autónoma de Andalucía".

13 Todo este proceso de reordenación lleva tiempo, como es lógico. Por ello hay previsto un régimen transitorio. Así, hasta que se produzca la constitución efectiva de las agencias creadas de acuerdo con la presente Ley, "las entidades instrumentales públicas que se extinguen como consecuencia de dicha 152 creación seguirán actuando conforme a lo establecido en su normativa reguladora” (Disposición transitoria única, Ley 1/2011). 


\section{HACIA UNA DELIMITACIÓN DE FUNCIONES ENTRE EL PERSONAL FUNCIONARIO Y LABORAL DE LAS NUEVAS AGENCIAS DE LA JUNTA DE ANDALUCÍA}

\section{Consideraciones previas sobre la normativa aplicable al personal de las nuevas agencias andaluzas}

Como apuntábamos anteriormente, son varias las cuestiones que podrían quedar planteadas aquí. Sin embargo, nuestro propósito en las líneas que siguen será el dejar sentado unos parámetros básicos a modo de hoja de ruta sobre los cuales deberían integrarse el personal de las nuevas agencias de la Junta de Andalucía. De entrada, podría pensarse que el legislador andaluz está otorgando preferencia por el personal con vínculo laboral para la ocupación de estos futuros puestos de trabajo.

Si recordamos entre la "maraña" de preceptos que hacían referencia a las nuevas agencias, las potestades administrativas y demás funciones a desarrollar, podemos extrapolar aquí otra vez un precepto clave en esta materia: la nueva redacción del art. 70.1 de la Ley 9/2007. Según el cual, “el personal de las agencias públicas empresariales se rige en todo caso por el Derecho Laboral, así como por lo que le sea de aplicación el Estatuto Básico del Empleado Público". Por su parte, en lo referente a las agencias de régimen especial, el personal podrá ser funcionario y personal sujeto a Derecho Laboral como así establece el nuevo art. 74.1 de la Ley $9 / 2007^{14}$.

Pues bien, de la lectura de estos preceptos podríamos pensar que el legislador andaluz no tiene claro cuál es la normativa aplicable al personal laboral de estas agencias. Por ello, con carácter previo, antes de entrar a analizar cuáles son las concretas funciones que deben desempeñar los funcionarios públicos de las nuevas agencias y cuáles pueden ser asumidas por personal laboral, es preciso dejar apuntado también aquí brevemente algunas notas sobre la normativa aplicable en materia de función pública, por todos ya conocida: el Estatuto Básico del Empleado Público (EBEP). Y, más concretamente, sobre su ámbito de aplicación, teniendo en cuenta la confusión que al respecto presenta la nueva Ley andaluza.

La regla general es la aplicación del EBEP al personal de toda Administración o entidad que, jurídicamente, tenga carácter público, es decir, personalidad jurídica pública. Lo esencial, como señala Sánchez Morón, es que se trate de "entes con personificación jurídica de Derecho administrativo y no de Derecho civil o mercantil. En consecuencia, están incluidos también en esa expresión las entidades públicas em-

14 Respecto al personal de las agencias administrativas, ya comentamos anteriormente que la única modificación al respecto se establece en la nueva redacción del artículo 65. 3 de la Ley 9/2007, según el cual las agencias administrativas se adscriben a una Consejería (o excepcionalmente a otra agencia administrativa) y nada se dice sobre el personal que se integra en éstas. 
presariales (a que se refieren los artículos 53 y siguientes de la LOFAGE y algunas leyes autonómicas), cuyo personal es laboral en su mayor parte”15.

No se aplica, en cambio, a sociedades y fundaciones del sector público, sino en lo previsto por la disposición adicional primera del EBEP. Así, se aplica al personal de las entidades del sector público empresarial y fundacional, los principios contenidos en Código de Conducta de los empleados públicos, los principios rectores del acceso al empleo público y de la selección (pero no las demás reglas de detalle) y la reserva de vacantes para personas con discapacidad. En lo demás, se aplica el Derecho del trabajo común ${ }^{16}$.

La cuestión tiene gran importancia pues, como sostiene este autor, "es de prever que la creación de este tipo de sociedades y fundaciones en mano pública siga en aumento. Más aún, una de las razones por las que se ha venido produciendo la huida del Derecho público, inclusive en el ámbito de la organización, y la preferencia por fórmulas características de la empresa privada es, justamente, la mayor flexibilidad del régimen de personal" "17. De esta forma, al menos en las referidas materias, sí les será de aplicación el EBEP ${ }^{18}$.

\section{Sánchez Morón (2007a): pág. 49.}

También están incluidos los entes públicos de naturaleza o régimen especial, entre ellos las Entidades Gestoras y la Tesorería General de la Seguridad Social y la Agencia Estatal de Administración Tributaria (con las excepciones que veremos más adelante). O por poner un último ejemplo, también se aplica al personal propio de mancomunidades municipales y consorcios públicos (salvo que éstos tengan, según sus estatutos, forma jurídica de sociedad, como a veces se establece), así como al personal de Comarcas, Cabildos y Consejos Insulares, y otras agrupaciones de municipios.

16 Desde esta perspectiva, como se expresó en el Informe de la Comisión de expertos para la elaboración y estudio del EBEP (en adelante, Comisión) no es aceptable que este tipo de opciones organizativas persiga o tenga como consecuencia la inaplicación de los principios constitucionales. De hecho, la legislación reciente ha reaccionado frente a esta situación y de ahí que la Ley de Fundaciones (art. 46.4) prevea, por lo que se refiere al sector público estatal, que la selección de su personal debe realizarse con sujeción a los principios de igualdad, mérito, capacidad y publicidad de la correspondiente convocatoria.

Del mismo modo, y para el caso de las entidades del sector empresarial público, el propio Derecho Comunitario en su Directiva 2004/18/CE establece la exigencia de aplicar los principios de la contratación pública (publicidad, igualdad y competencia). En efecto, el concepto comunitario de Administración está más orientado sobre una idea más funcional y objetiva que subjetiva. De este modo, la noción de organismo público que preside el elemento subjetivo en materias como la contratación pública o la prestación de servicios de interés económico general, no se identifica con el concepto nacional de Administración pública sino que es más amplio y flexible, en el que tanto las empresas del sector público como operadores privados pueden tener cabida.

En este sentido, el concepto clave para la contratación pública es la noción de "poder adjudicador" que, a su vez, deriva del concepto comunitario de “organismo público”. Así, según la Jurisprudencia del TJCE, para ser calificada de organismo de Derecho Público en el sentido de las Directivas comunitarias, una entidad debe cumplir tres requisitos acumulativos, que se desprenden de la STJCE de 15 de enero de 1998 "Mannesmann Anlagenbau Austria y otros" o la STJCE de 15 de mayo de 2003 "Comisión/España", a saber: a) Ser un organismo creado para satisfacer específicamente necesidades de interés general que no tenga carácter industrial o mercantil; b) Tener personalidad jurídica; c) Que su actividad dependa estrechamente del Estado, de los entes territoriales o de otros organismos de Derecho Público.

17 Sánchez Morón (2007a): 79.

18 En esta misma línea, como expresó el Tribunal Constitucional en su Sentencia 25/1983, hay que 154 tener en cuenta que la noción de poderes públicos que utiliza nuestra Constitución (arts. 9, 27, 39 a 41, 44 
Queda claro, pues, que el EBEP sí se aplica no sólo al personal funcionario sino también al laboral de las nuevas agencias de la Junta de Andalucía ya que todas son entidades públicas, con personalidad jurídica pública, y eso es lo importante. Puesto que el EBEP, como normativa básica en materia de función pública, se aplica también al conjunto de trabajadores que desarrollan su actividad profesional o laboral en el seno de las entidades públicas vinculadas o dependientes de cualquier Administración Pública ${ }^{19}$.

a 51, 53 y otros) sirve "como concepto genérico que incluye a todos aquellos entes (y sus órganos) que ejercen un poder de imperio, derivado de la soberanía del Estado y procedente, en consecuencia, a través de una mediación más o menos larga, del propio pueblo. Esta noción no es sin duda coincidente con la de servicio público, pero lo "público" establece entre ambas una conexión que tampoco cabe desconocer, pues las funciones calificadas como servicios públicos quedan colocadas por ello, y con independencia de cuál sea el título (autorización, concesión, etc.) que hace posible su prestación, en una especial relación de dependencia respecto de los poderes públicos".

Esta relación, sigue diciendo el Tribunal Constitucional, "se hace tanto más intensa, como es obvio, cuanto mayor sea la participación del poder en la determinación de las condiciones en las que el servicio ha de prestarse y en la creación, organización y dirección de los entes o establecimientos que deben prestarlo. Cuando el servicio queda reservado en monopolio a un establecimiento cuya creación, organización y dirección son determinadas exclusivamente por el poder público, no cabe duda de que es éste el que actúa, a través de persona interpuesta, pero en modo alguno independiente. La necesidad de hacer más flexible el funcionamiento de estos entes interpuestos puede aconsejar el que se de a su estructura una forma propia del Derecho privado y que se sometan a éste los actos empresariales que debe llevar a cabo para el ejercicio de su función, pero ésta, en cuanto dirigida directamente al público como tal, ha de entenderse vinculada al respeto de los derechos y libertades reconocidos en el capítulo segundo del título I de la Constitución, según dispone el artículo 53.1 de ésta y, en consecuencia, los ciudadanos protegidos también frente a ella con los instrumentos que el ordenamiento les ofrece para salvaguarda de sus derechos fundamentales frente a los actos del poder".

Precisamente es, desde esta línea jurisprudencial, por la que el EBEP viene a reforzar estas garantías y principios constitucionales del conjunto del personal que desempeña funciones en este tipo de entidades. Y ello, al menos, por lo que se refiere a los principios rectores de acceso al empleo público, a las medidas de integración de las personas con discapacidad y los valores de ética y conducta que han de quedar salvaguardados por el conjunto de los empleados públicos que, de una forma u otra, presta sus servicios en las Administraciones públicas.

19 El criterio fundamental para alcanzar ese resultado ha sido "extender al personal laboral principios y reglas tradicionalmente propios del personal funcionario y no tanto, a la inversa" (Sánchez Morón (2007a): pág. 49).

En efecto, como señaló el Informe de la Comisión de Expertos para el estudio y preparación del Estatuto Básico del Empleado Público (en adelante, Comisión) "no se proponía unificar la relación estatutaria y la relación laboral de empleo público en un régimen único, sino que el EBEP incluyera unos mismos principios y valores esenciales para el conjunto de los profesionales y trabajadores del sector público, sin perjuicio de las normas específicas aplicables al personal funcionario o al personal laboral que, justificadamente, proceda mantener" (MAP (2005): 89 y ss.).

En cualquier caso, como indica el autor, la doble cualidad de normas de función pública y de legislación laboral que tienen al mismo tiempo muchos de los preceptos del EBEP acarrea consecuencias distintas a efectos del desarrollo y concreción de esos preceptos. En lo que se refiere a los funcionarios públicos, la legislación de desarrollo habrá de ser aprobada por las Cortes Generales (y, obviamente, por el Gobierno y otros órganos inferiores cuando se trate de reglamentos) o por las Comunidades Autónomas (leyes y reglamentos de función pública) en el ámbito de sus respectivas competencias.

En cambio, por lo que se refiere al personal laboral, en lo no regulado por el EBEP habrá de aplicarse la legislación laboral general, esto es, las acordadas en convenio colectivo. Debe destacarse que la legislación laboral es o debe ser, necesariamente, legislación del Estado, de conformidad con lo dispuesto en el artículo 149.1.7.a de la Constitución, pues las Comunidades Autónomas carecen de toda competencia en la materia. Sólo a través de los convenios colectivos que firmen con los representantes de sus empleados 
Este es, en definitiva, el planteamiento que se deriva del EBEP y no otro. Por mucho que algunos sectores doctrinales estén empeñados en desvirtuar la filosofía y espíritu del Estatuto Básico, a saber ${ }^{20}$ : Establecer unas reglas y principios comunes para todo el personal que presta sus servicios en la Administración Pública (cuyo ámbito de aplicación se extiende también a las entidades de derecho público), con independencia del vínculo que les una a la organización, aunque respetando las lógicas diferenciaciones que, en uno y otro caso, deban establecerse como así viene señalando la doctrina más especializada en la materia (Sánchez Morón, Castillo Blanco, Palomar Olmeda, Sala Franco, Jiménez Asensio, etc. $)^{21}$.

\section{Los criterios a tener en cuenta en la delimitación de funciones del personal de las nuevas agencias andaluzas}

\section{a) Del EBEP y demás legislación anterior no derogada expresamente}

Una vez aclarada la incertidumbre generada por el legislador andaluz sobre la normativa aplicable al personal afectado por la reordenación de su sector público, pasamos ahora a la difícil tarea de delimitar las concretas funciones que deben corresponder al personal funcionario y cuáles otras pueden asignarse al personal laboral de las nuevas agencias de la Junta de Andalucía.

En este sentido, hay que poner de relieve, en primer lugar, que la posibilidad de contar en cada entidad con personal funcionario y personal laboral no debe significar que sea indiferente asignar cualquier puesto de trabajo a personal de uno u otro tipo. Por el contrario, una regla de orden elemental exige diferenciar con claridad los puestos de trabajo y las funciones que deben desempeñar el personal funcionario y el laboral.

podrán las Comunidades Autónomas (y las Entidades Locales) participar en la adopción de normas (convencionales) que desarrollen el EBEP para el personal laboral.

20 En este sentido, hay que recordar que la Audiencia Nacional en su Auto No 63/2010, de 28 de octubre, con ocasión de la impugnación de las organizaciones sindicales sobre el Real Decreto-ley 8/2010, de 20 de mayo, por el que se adoptan medidas extraordinarias para la reducción del déficit público, declaró a los efectos que aquí nos interesa lo siguiente: “... pudiendo concluirse, por consiguiente, que las relaciones laborales entre las Administraciones publicas se rigen básicamente por la legislación laboral y por los convenios colectivos, salvo que el EBEP disponga su prioridad aplicativa, lo que sucede muy excepcionalmente en dicha norma legal".

21 Para tener una visión de conjunto sobre el empleo público tras la aprobación del EBEP, sin ánimo de ser exhaustivo, pueden consultarse los siguientes trabajos: AA.VV. (2007): Comentarios a la Ley del Estatuto Básico del Empleado Público, Valladolid, Ed. Lex Nova,; AA.VV. (2007): Estatuto Básico del Empleado Público, Madrid, Ed. La Ley-El Consultor; AA.VV. (2007): El Estatuto Básico del empleado público y su incidencia en el ámbito local, Granada, Ed. CEMCI,; AA.VV. (2008): Comentarios a la Ley 7/2007, del Estatuto Básico del Empleado Público, Pamplona, Ed. Aranzadi,; AA.VV. (2008): El Estatuto Básico del Empleado Público. Comentario Sistemático a la Ley 7/2007, de 12 de abril, de 2007, Granada, Ed. Comares,; AA.VV. (2008): El Estatuto Básico del Empleado Público. Propuestas de desarrollo legislativo por parte de las Comunidades Autónomas, Barcelona, Ed. CEMICAL;; AA.VV. (2009): Manual de Empleo Público, Madrid, Ed. Iustel; JIMÉNEZ ASENSIO, Rafael; CASTILLO BLANCO, Federico (2009): Informe sobre el empleo público local. Balance y propuestas para su racionalización en el marco de la reforma del empleo público, Madrid, Ed. Fundación Democracia y Gobierno Local. 
En este contexto, y en atención a la reserva de Ley en materia de función pública que establece el art. 103.3 CE, la STC 99/1987 declaró que "son las leyes reguladoras de la función pública las que deben determinar en cada caso qué funciones públicas corresponde ejercer al personal funcionario en exclusiva y cuáles pueden ser desempeñadas por el personal laboral. Y, esta decisión no puede ser remitida en blanco por la Ley a los Gobiernos y Administraciones Públicas".

Así, lo confirma también la STS de 2 de diciembre de 2003, al señalar que: "el artículo 103.3 de la Constitución (RCL 1978, 2836) ha reservado a la Ley de regulación de la situación personal de los funcionarios públicos y de su relación de servicio o "régimen estatutario", por emplear la expresión que figura en el artículo 149.1.18ª de la CE y correspondiendo sólo a la Ley la regulación del modo de provisión de puestos de trabajo al servicio de las Administraciones Públicas, pues no otra cosa se desprende de la opción genérica de la Constitución (arts. 103.3 y 149.1.18) en favor del régimen estatutario para los servidores públicos y de la consiguiente exigencia de que las normas que permitan excepcionar tal previsión constitucional sean dispuestas por el Legislador, garantizándose, de este modo, una efectiva sujeción de los órganos administrativos, a la hora de decidir qué puestos concretos de trabajo puedan ser cubiertos por quienes no posean la condición de funcionario, de conformidad con los criterios del Tribunal Constitucional".

En consecuencia, la Ley debe establecer criterios suficientemente claros al respecto, a fin de que puedan concretarse después al elaborar las relaciones de puestos de trabajo o instrumentos semejantes de ordenación (art. 74 del EBEP). Y esta exigencia se recoge expresamente en el EBEP (art. 11.2) cuando dice que las Leyes de Función Pública que se dicten en desarrollo de este Estatuto establecerán los criterios para la determinación de los puestos de trabajo que pueden ser desempeñados por personal laboral, respetando en todo caso lo establecido en el art. 9.2 que veremos seguidamente. De hecho, así es como se ha venido haciendo tanto por la legislación del Estado como por las leyes de función pública de las Comunidades Autónomas ${ }^{22}$.

22 Por el contrario, para la Administración Local el art. 92 de la LBRL partía de un criterio diferente, ya que identificaba sólo las funciones públicas reservadas exclusivamente a personal sujeto al estatus funcionarial, en términos bastantes genéricos: "las que impliquen ejercicio de autoridad, las de fe pública y asesoramiento legal preceptivo, las de control y fiscalización interna de la gestión económico-financiera y presupuestaria y las de contabilidad y tesorería y, en general, aquellas que en desarrollo de la presente Ley se reserven a funcionarios para la mejor garantía de la objetividad, imparcialidad e independencia en el ejercicio de la función".

No obstante el carácter abstracto de algunos de los criterios de reserva, la STC 37/2002, de 14 de febrero, consideró que el art. 92.2 de la LBRL respetaba la reserva de Ley, al establecer criterios suficientes de identificación de los puestos o funciones que no pueden ser desempeñados por personal laboral. En efecto, como señaló el Alto Tribunal en aquella ocasión, la duda de constitucionalidad de este precepto se suscitaba con la expresión “y, en general, aquellas que en desarrollo de la presente Ley, se reserven a los funcionarios para la mejor garantía de la objetividad, imparcialidad o independencia en el ejercicio de la función".

Como señaló el TC, si bien es cierto que "el precepto cuestionado no especifica qué concretas funciones han de ser desempeñadas por personal sujeto al estatuto funcionarial, remitiendo su determinación al desarrollo del mismo. Sin embargo, tal remisión, limitada a la clase de funciones referida, no puede esti- 
Concretamente, nos Ilama la atención esta preferencia del legislador andaluz por el personal laboral que parece olvidar su propia Ley 6/1985, de 28 de noviembre, de Ordenación de la Función Pública de la Junta de Andalucía, que no ha sido derogada expresamente y en cuyo art. 12.1, establece que: " Los puestos de trabajos figurarán en una relación, en la que individualmente aparezca cada uno de ellos con las siguientes circunstancias mínimas:

a) Denominación;

b) Características esenciales;

c) Ente, departamento y centro directivo en que orgánicamente este integrado;

d) Adscripción a funcionarios o laborales en atención a la naturaleza de su contenido;

e) Requisitos exigidos para su desempeño, y, además, tratándose de funcionarios;

f) Indicación de si el puesto de trabajo es de libre designación;

g) Nivel en que ha sido clasificado, y

h) Complemento especifico, con indicación de los factores que se retribuyen con el mismo y su valoración resultante.

Y añade, en el párrafo segundo de este mismo artículo, que: “A los efectos previstos en la letra d) del apartado anterior, con carácter general, los puestos de trabajo de la administración de la Junta de Andalucía y de sus organismos autónomos, serán desempeñados por funcionarios públicos". Únicamente podrán exceptuarse de la regla anterior y adscribirse a personal laboral en la correspondiente relación de puestos de trabajo:

marse incondicionada o carente de límites pues en el propio precepto se disponen los criterios o parámetros que han de inspirar en su desarrollo la determinación de las funciones que han de ser desempeñadas por funcionarios públicos, cuales son la garantía de la objetividad, imparcialidad e independencia en el ejercicio de la función pública. Criterios que, aunque genéricos en su formulación, poseen un contenido que es susceptible de ser delimitado en cada caso en concreto en atención a las características de la función o puesto de trabajo del que se trata e imponen, por lo tanto, una efectiva sujeción en la determinación de las concretas funciones, no calificadas como necesarias en todas las corporaciones locales, que han de ser desempeñadas por personal sujeto al estatuto funcionarial".

Es más, considerando en su totalidad el art. 92.2 LBRL, y no aislando, el precepto contenía, como señala el Alto Tribunal, "una determinación material que sería, por sí, suficiente de las funciones que han de ser desempeñadas por funcionarios públicos y, a sensu contrario, de las que no pueden ser encomendadas al personal contratado, el cual no podrá ocupar aquellos puestos de trabajo que impliquen el ejercicio de las funciones enumeradas en el primer inciso del art. 92.2 LBRL, esto es, las que impliquen ejercicio 158 mejor garantía de objetividad, imparcialidad e independencia en el ejercicio de la función pública". 
- Los puestos de naturaleza no permanente y aquellos cuyas actividades se dirijan a satisfacer necesidades de carácter periódico y discontinuo.

- Los puestos cuyas actividades sean propias de oficios, así como los de vigilancia, custodia, porteo y otros análogos.

- Los puestos de carácter instrumental correspondientes a las áreas de mantenimiento y conservación de edificios, equipos e instalaciones, artes gráficas, encuestas, protección civil y comunicación social, así como los puestos de las áreas de expresión artística y los vinculados directamente a su desarrollo, servicios sociales y protección de menores.

- Los puestos correspondientes a áreas de actividades que requieran conocimientos técnicos especializados cuando no existan cuerpos de funcionarios cuyos miembros tengan la preparación específica para su desempeño.

Como podemos comprobar, la propia Ley de Función Pública de Andalucía que sigue en vigor en la actualidad, establece la preferencia, con carácter general, por la ocupación de los puestos de trabajo por el personal funcionario y configurando, en consecuencia, al personal laboral como una excepción dentro de esta Administración autonómica en los supuestos señalados más arriba. Una regla que, sin embargo, en la nueva Ley 1/2011 parece invertirse para la integración del personal en las nuevas agencias.

Y es que, en efecto, en Andalucía como en otras muchas Comunidades Autónomas, la delimitación de las funciones y puestos propios del personal funcionario y del personal laboral se ha venido realizando también a través de leyes especiales reguladoras de diferentes sectores de la acción pública, por leyes de organización administrativa o por las leyes singulares de creación de organismos o entes públicos determinados como ante la que nos encontramos en el presente caso que nos ocupa.

Sin embargo, hay que tener en cuenta que hasta la entrada en vigor del EBEP, no existía un precepto legal de carácter básico que estableciera un criterio general de reserva de funciones al personal funcionario, aplicable en todas las Administraciones y en todas las áreas del empleo público. Y, precisamente, este vacío es el que colma el art. 9.2 del EBEP. En su virtud, será necesario atribuir exclusivamente a funcionarios públicos el ejercicio de funciones que impliquen la participación directa o indirecta en el ejercicio de las potestades públicas o en la salvaguarda de los intereses generales del Estado y de las Administraciones Públicas.

No obstante, este primer acercamiento restrictivo al concepto de ejercicio de potestades públicas, como señala Cantero Martínez, "no soluciona del todo los múltiples problemas interpretativos que plantea la redacción de esta cláusula, toda vez que resulta muy difícil poder marcar una línea divisoria entre lo que sería el ejercicio estricto de este tipo de funciones y las tareas de auxilio o colaboración a las mismas 
que podrían realizar otros empleados, pero que también pueden resultar imprescindibles para el adecuado ejercicio de aquéllas y que, en consecuencia, también podrían considerarse incluidas en esta cláusula como "participación indirecta" en el ejercicio de las potestades administrativas"23.

Por ello, hay que tener en cuenta también que aunque, a priori, se trata de un criterio muy abstracto y general, expresado a través de conceptos indeterminados, su interpretación debe hacerse conforme a lo señalado por la Comisión de Expertos que se basó, a su vez, en la jurisprudencia del Tribunal de Justicia de la Unión Europea para definir en qué casos los Estados miembros de la Unión pueden reservar funciones o puestos de trabajo en la Administración a ciudadanos de su propia nacionalidad, con exclusión de los ciudadanos de los demás Estados miembros ${ }^{24}$.

Desde esta perspectiva, pues, el criterio que se fija por la jurisprudencia comunitaria para excepcionar el principio de libre circulación de los trabajadores en el ámbito de la Unión Europea es el que trae ahora al Estatuto Básico para definir las funciones que deben reservarse en todo caso al personal funcionario en nuestro país. Y ello porque hay en ambos casos una identidad de razón: Se trata de aquellas funciones que corresponden al núcleo esencial de la actividad administrativa ${ }^{25}$.

En consecuencia, como señala Sánchez Morón, “los conceptos de "ejercicio de las potestades públicas" y de "salvaguardia de los intereses generales" no deberían ser objeto de una interpretación extensiva, como seguramente pretenderán los partidarios de la funcionarización general del empleo público. El primero de ellos remite simplemente a aquellos puestos de trabajo que suponen el ejercicio de funciones de

23 López Benítez, Mariano; Cantero Martínez, Josefa; Puerta Seguido, Francisco (2009): 98 y ss.

24 Véase al respecto el informe de la Comisión en MAP (2005): Informe de la Comisión para el estudio y preparación del Estatuto Básico del Empleado Público, INAP, Madrid.

25 Como señala López Benítez, Mariano; Cantero Martínez, Josefa; Puerta Seguido, Francisco (2009): 106 y ss.: "el actual artículo 39.4 del Tratado Constitutivo de la Comunidad Europea (antiguo 48.4 y futuro artículo 45.4 del Tratado de Funcionamiento de la Unión Europea) permite la posibilidad de que los Estados miembros puedan establecer limitaciones a este principio y excluir de la libre circulación de trabajadores a los empleos en la Administración Pública. A partir de ahí, la jurisprudencia del Tribunal de Justicia ha venido realizando una interpretación funcional de lo que haya de entenderse por empleos en la Administración Pública, limitándolo única y exclusivamente a aquellos empleos que supongan una participación en el ejercicio de poder público y que tienen por objeto la salvaguardia de los intereses generales del Estado o de las Administraciones Públicas".

Según la jurisprudencia del Tribunal de Justicia, sigue diciendo, "el concepto de Administración Pública a efectos del artículo 39, apartado 4, debe interpretarse y aplicarse uniformemente en toda la Comunidad y no es posible por tanto dejarlo a la absoluta discreción de los Estados miembros (sentencias de 12 de febrero de 1974, Sotgiu, 152/73, apartado 5 y la de 17 de diciembre de 1980, asunto Comisión/Bélgica 149/79). A partir de ahí, el Tribunal ha reiterado que esta disposición se refiere a "los empleos que implican una participación, directa o indirecta, en el ejercicio del poder público y en las funciones que tienen por objeto la salvaguardia de los intereses generales del Estado y de las demás entidades públicas y que suponen pues, por parte de sus titulares, la existencia de una relación particular de solidaridad con el Estado, así como la reciprocidad de derechos y deberes que son el fundamento del vínculo de nacionalidad" (Sentencias de 30 de septiembre de 2003, asunto Ander y otros, C-47/02; de 31 de mayo de 2001, asunto C-283/99 y de 2 de julio de 1996, C-290/94, entre otras muchas)". 
autoridad, tales como la elaboración y aprobación de los actos administrativos limitativos de derechos, las actividades de inspección y sanción, la exacción de tributos o la emanación de órdenes de policía. El segundo alude a otras funciones que son indispensables para el ejercicio del poder público"26.

Por tanto, la forma más correcta de interpretar el precepto y resolver las dudas que su aplicación va a plantear es remitirse a los criterios que la Comisión Europea y la propia legislación interna, concretamente, el Real Decreto 543/2001, de 18 de mayo, sobre acceso al empleo público de la Administración General del Estado y sus Organismos Autónomos de nacionales de otros Estados a los que es de aplicación el derecho a la libre circulación de trabajadores.

Así, como establece este Real Decreto, los puestos de trabajo que impliquen la participación directa o indirecta en el ejercicio del poder público y en las funciones que tienen por objeto la salvaguarda de los intereses del Estado o de las demás Administraciones públicas quedarán reservados a los empleados públicos de nacionalidad española. Y que, por tanto, serán los órganos competentes quienes determinarán los puestos de trabajo para cuyo desempeño sea exigible la nacionalidad española, especificándolo en las correspondientes relaciones de puestos de trabajo, catálogos o plantillas (art. 5 del Real Decreto 543/2001).

En este sentido, y a título de ejemplo, se detallan los Cuerpos y Escalas de la función pública estatal excluidos del principio comunitario de libre circulación de trabajadores, entre los que figuran, a los efectos que aquí nos interesan, la Escala de Funcionarios de Administración Local con habilitación de carácter nacional, así como en el ámbito de la Agencia Estatal de Administración Tributaría, el Cuerpo Superior de Inspectores de Hacienda del Estado o el Cuerpo General Administrativo de la Administración del Estado en su Especialidad de Agentes de la Hacienda Pública, entre otros $^{27}$.

26 Sánchez Morón, Miguel (2007b): 91.

Como señala también López Benítez, Mariano; Cantero Martínez, Josefa; Puerta Seguido, Francisco (2009): 106 y ss.: "En desarrollo de la jurisprudencia comunitaria se señalaron inicialmente determinados sectores de actividad incardinados dentro de la función pública a los que sería aplicable la libertad de circulación de trabajadores. Se abrían a nacionales de otros Estados comunitarios el sector investigador, docente, de correos, asistencia y aquellos otros a los que según el Derecho Comunitarios les fuera aplicable la libre circulación de trabajadores. Posteriormente se adoptó un criterio diferente, de tal forma que la Ley 17/1993, de 23 de diciembre, modificada por la Ley 55/1999, de 29 de diciembre, dispuso como regla general el acceso de los nacionales de los Estados miembros de la Unión Europea en condiciones de igualdad a todos los empleos públicos, "salvo que impliquen una participación directa o indirecta en el ejercicio del poder público y se trate de funciones que tienen por objeto la salvaguarda de los intereses del Estado o de las Administraciones Públicas". Aparece así recogida expresamente y por vez primera en una norma con rango de ley y carácter básico esta cláusula que ahora nos ocupa”. En desarrollo de esta Ley, se aprueba el Real Decreto 543/2001, de 18 de mayo, sobre acceso al empleo público de la Administración General del Estado y sus Organismos Públicos de nacionales de otros Estados a los que es de aplicación el derecho a la libre circulación de trabajadores.

27 Por lo que se refiere a la Administración Local, el propio EBEP, en su disposición adicional segunda, viene a establecer cuáles son las funciones reservadas a funcionarios: "Son funciones públicas, cuyo 
Además, hay que poner de relieve que, desde un punto de vista jurídico, tampoco es fácil interpretar qué se entiende a estos efectos por funciones que impliquen ejercicio de autoridad, ya que no existe una definición legal de las mismas. No obstante, está claro que son funciones de esa naturaleza las que conllevan la potestad de dictar actos administrativos de obligado cumplimiento o actividades de inspección e instrucción de expedientes de carácter sancionador o limitativo de derechos de los ciudadanos.

Por tanto, el ejercicio de otras actividades públicas, inclusive las meramente auxiliares de aquéllas o las que consistan en prestación de servicios al público, no requiere que sean reservadas en principio a funcionarios públicos. Aunque tampoco están vedadas a empleados con estatuto de funcionario, pues, dependerá del criterio adoptado por cada entidad pública.

En todo caso, como indica Sánchez Morón, hay que tener presente que "la interpretación correcta es la que coincide con el ejercicio de aquellas funciones públicas excluidas del principio de libre circulación de trabajadores en la Unión Europea y así lo confirma también el art. 57.1 del EBEP para excepcionar el derecho de acceso en condiciones de igualdad de los nacionales miembros de otros Estados de la Unión Europea a la condición de funcionario en España"28.

cumplimiento queda reservado exclusivamente a funcionarios, las que impliquen ejercicio de autoridad, las de fe pública y asesoramiento legal preceptivo, las de control y fiscalización interna de la gestión económico-financiera y presupuestaria, las de contabilidad y tesorería".

Aunque llama la atención que el enunciado no coincida en mayor medida con el art. 9.2 pues en la disposición adicional la expresión "ejercicio de autoridad" sustituye a la de "ejercicio de potestades públicas" y porque no se hace referencia alguna a la "salvaguardia de los intereses generales", hay que decir que hay una cierta coincidencia de criterio: La reserva básica de funciones y puestos de trabajo a funcionarios públicos tiene un alcance limitado.

Como señala Sánchez Morón (2007a): 72 y ss.: “... resulta difícil saber hasta qué punto la falta de coherencia de la disposición adicional segunda con el artículo 9.2 del propio EBEP tiene una fundamentación bien meditada o es fruto de la inadvertencia. Lo que en todo caso resulta es que las funciones reservadas por la Ley básica a funcionarios en las Corporaciones Locales son menores que las reservadas en las demás Administraciones Públicas, pues se limitan a las que impliquen ejercicio de autoridad, además de las atribuidas a los funcionarios con habilitación de carácter estatal. Eso podría tener como consecuencia que "el porcentaje de empleados con contrato laboral en la Administración Local siga siendo muy superior al que existe en las Administraciones Estatal y Autonómica. Pero, por supuesto, ello no quiere decir que, aparte de Secretarios, Interventores y Tesoreros, sólo los empleados que ejercen funciones de autoridad puedan tener y vayan a tener estatuto de funcionarios. Corresponderá a cada Entidad Local, en el marco de las leyes y respetando aquel límite, determinar qué parte de sus empleados son funcionarios o laborales. El resultado dependerá del criterio político que cada Corporación adopte y de las reivindicaciones de funcionarización que constantemente promueven o apoyan los sindicatos".

28 Sánchez Morón, (2007b): 92: En este sentido, resulta de gran interés tener en cuenta la STJUE de 24 de mayo de 2011 donde el Tribunal con el fin de determinar si las actividades de los notarios están relacionadas con el ejercicio del poder público en el sentido del Tratado CE, el Tribunal de Justicia analiza las competencias que éstos tienen atribuidas en los Estados miembros en cuestión y recuerda, en primer lugar, que únicamente las actividades que estén directa y específicamente relacionadas con el ejercicio del poder público pueden sustraerse a la aplicación del principio de libertad de establecimiento. Así, a juicio del Tribunal, la función de autentificación atribuida a los notarios no está directa y específicamente relacionada con el ejercicio del poder público. El hecho de que determinados actos o contratos deban 
Ahora bien, ello no significa que sólo esas funciones, estrictamente interpretadas, vayan a ser exclusivas de los funcionarios públicos. Muy al contrario, la reserva básica debe ser completada por lo que dispongan al respecto las leyes de función pública del Estado y de las Comunidades Autónomas. De hecho, el Estatuto Básico no deroga el art. 15.1 C) de la LMRFP, donde se establece que los puestos de trabajo de la Administración del Estado, sus organismos autónomos y entidades gestoras de la Seguridad Social se desempeñarán "con carácter general” por funcionarios públicos y donde se prevén las excepciones a esta regla29.

De esta forma, se exceptúan de la regla anterior y podrán desempeñarse por personal laboral, por ejemplo, los puestos de naturaleza no permanente y aquellos cuyas actividades se dirijan a satisfacer necesidades de carácter periódico y discontinuo; los puestos correspondientes a áreas de actividades que requieran conocimientos técnicos especializados cuando no existan Cuerpos o Escalas de funcionarios cuyos miembros tengan la preparación específica necesaria para su desempeño; o, por

autentificarse obligatoriamente so pena de nulidad no desvirtúa esta conclusión, ya que no es infrecuente que la validez de diferentes actos esté supeditada a requisitos de forma o incluso a procedimientos obligatorios de validación. De igual modo, el hecho de que la actividad de los notarios persiga un objetivo de interés general consistente en garantizar la legalidad y la seguridad jurídica de los actos celebrados entre particulares no basta por sí mismo para considerar que esta actividad está directa y específicamente relacionada con el ejercicio del poder público. En efecto, las actividades realizadas en el marco de diferentes profesiones reguladas implican frecuentemente la obligación de que las personas que las ejercen persigan tal objetivo sin que por ello estas actividades se consideren como una manifestación del poder público.

En suma, el Tribunal de Justicia analiza las demás actividades encomendadas a los notarios en los Estados miembros y llega a la conclusión de que tampoco éstas implican una relación con el ejercicio del poder público, ya que la mayor parte de tales actividades se ejercen bajo la supervisión de un juez o conforme a la voluntad de los clientes.

29 Así, se exceptúan de la regla anterior y podrán desempeñarse por personal laboral:

a) Los puestos de naturaleza no permanente y aquellos cuyas actividades se dirijan a satisfacer necesidades de carácter periódico y discontinuo.

b) Los puestos cuyas actividades sean propias de oficios, así como los de vigilancia, custodia, porteo y otros análogos.

c) Los puestos de carácter instrumental correspondientes a las áreas de mantenimiento y conservación de edificios, equipos e instalaciones, artes gráficas, encuestas, protección civil y comunicación social, así como los puestos de las áreas de expresión artística y los vinculados directamente a su desarrollo, servicios sociales y protección de menores.

d) Los puestos correspondientes a áreas de actividades que requieran conocimientos técnicos especializados cuando no existan Cuerpos o Escalas de funcionarios cuyos miembros tengan la preparación específica necesaria para su desempeño;

e) Los puestos de trabajo en el extranjero con funciones administrativas de trámite y colaboración y auxiliares que comporten manejo de máquinas, archivo y similares;

f) Los puestos con funciones auxiliares de carácter instrumental y apoyo administrativo.

Asimismo, los organismos públicos de investigación podrán contratar personal laboral en los términos previstos en el artículo 17 de la Ley 13/1986, de 14 de abril, de Fomento y Coordinación General de la Investigación Científica y Técnica.

Por el contrario, la mayoría del personal sanitario y del personal docente seguirán teniendo un régimen estatutario, porque así lo dispone su legislación específica en virtud de una larga tradición que no es previsible vaya a cambiar. Y ello aunque no tengan por qué ser funcionarios públicos de acuerdo con el art. 9.2, siguiendo los criterios de la jurisprudencia europea que aplica el principio de libertad de circulación de trabajadores. 
poner un último ejemplo, los puestos con funciones auxiliares de carácter instrumental y apoyo administrativo.

Así, además, lo ha entendido y declarado, por cierto, el MAP en las Instrucciones para la aplicación del EBEP en la Administración General del Estado y sus organismos públicos, como también en los Criterios para la aplicación del EBEP en el ámbito de la Administración Local ${ }^{30}$.

Toda esta legislación, por tanto, sigue en vigor y lo único que el nuevo art. 9.2 del EBEP añade al respecto es un límite mínimo a su eventual reforma. La regla básica del art. 9.2 del EBEP es, como señala Sánchez Morón, “muy abierta y no acaba con la polémica acerca de qué grupos de empleados públicos deben tener necesariamente o preferentemente la condición de funcionarios, de la misma manera que no acaba con la dialéctica entre partidarios de una mayor laboralización del empleo público (que se está extendiendo fundamentalmente a través de la creación de nuevos entes públicos de todo tipo) y los de una mayor funcionarización, perseguida por buena parte de los empleados con contrato laboral y por los sindicatos, como garantía superior de estabilidad en el empleo" ${ }^{31}$.

En efecto, como señala también Cantero Martínez, determinar "la futura extensión de este colectivo (personal laboral) en la Administración o las funciones concretas que podrá realizar a día de hoy es una incógnita. Siguiendo la doctrina establecida en la Sentencia del Tribunal 99/1987, de 11 de junio, reiterada posteriormente, entre otras, en la STC 235/2000, de 5 de octubre y en la 37/2002, de 14 de febrero, debe seguir entendiéndose que la regla general es la de ocupación funcionarial de los puestos de trabajo en la Administración, que ahora incluso se refuerza con la reserva de funciones al funcionario que efectúa el artículo 9.2 del Estatuto. Debe ser, pues, la ley la que determine las funciones que pueden ser desempeñadas por personal laboral. Una vez respetada la reserva mínima de funciones a quienes ostenten la condición de funcionarios que establece el artículo 9.2, serán después las leyes que elaboren las Asambleas Legislativas de las Comunidades Autónomas y la Ley de las Cortes Genera-

30 En efecto, como señala el MAP en los Criterios de aplicación del EBEP en el ámbito de la Administración local, continúan en vigor las normas en materia de provisión y movilidad aplicables a los funcionarios propios de las Entidades Locales, ya que la regulación que establece el EBEP sobre esta materia producirá efectos a partir de la entrada en vigor de las leyes de Función Pública que se dicten en desarrollo del mismo. Véase también la Resolución de 21 de junio de 2007, de la Secretaría General para la Administración Pública, por la que se publican las Instrucciones, de 5 de junio de 2007, para la aplicación del Estatuto Básico del Empleado Público en el ámbito de la Administración General del Estado y sus organismos públicos.

31 Sánchez Morón (2007b): 93: «Lo que ocurre, como señala el autor. «es que quizá ahora, si se cumplen las previsiones de la Comisión de Expertos, la polémica sobre esta cuestión podrá perder fuerza, dado que el EBEP reduce significativamente las diferencias de régimen jurídico entre los funcionarios y el personal laboral al servicio de las Administraciones Públicas». Y más aún, con el personal laboral que tiene carácter fijo y que esté desempeñando funciones de personal funcionario, o pase a desempeñarlas en virtud de pruebas de selección o promoción convocadas antes de la entrada en vigor del EBEP y que podrán seguir desempeñándolas (disposición transitoria segunda del EBEP)». 
les para el ámbito de la Administración General del Estado las que abran o reduzcan el abanico laboralizador en sus respectivos ámbitos"32.

En cualquier caso, interesa dejar apuntado aquí nuevamente el sentido de algunas de las resoluciones judiciales más recientes que vienen a complementar el conjunto de criterios de delimitación funcional de los trabajadores del sector público. Así, por ejemplo, puede citarse la STSJ de la Comunidad Valenciana 1105/2001, de 25 de octubre, cuando señala que: "Como ya se ha indicado en anteriores Sentencias de esta Sala -cual la de 22-2-2001, recaída en recurso 1904/1998- el artículo 169.1 del Texto Refundido de Disposiciones Legales vigentes en materia de Régimen Local, aprobado por Real Decreto Legislativo 781/1986 establece que "corresponde a los funcionarios de la Escala de Administración General el desempeño de las funciones comunes al ejercicio de la actividad administrativa". En consecuencia los puestos de trabajo predominantemente burocráticos habrán de ser desempeñados por funcionarios Técnicos, Administrativos o Auxiliares de Administración General”.

En esta línea, e incluso en términos mucho más restrictivos, se pronuncia también la STSJ de Aragón 35/2007, de 30 de enero, cuando expresa que: "el Tribunal entiende que el carácter instrumental no puede atribuirse más que al puesto de Técnico de Difusión Cultural de la Institución Fernando el Católico y para el nombramiento de personal laboral por tener conocimientos técnicos especializados, es requisito indispensable que no existan funcionarios con la preparación física necesaria para el desempeño del puesto, lo que no parece posible dado el perfil que para los puestos de estas características describe el informe de mención" 33 .

O, por poner un último ejemplo, podemos citar las sentencias del Tribunal Superior de Justicia de Andalucía n597/2008, de 25 de mayo de 2009, y la nº 113/2009, de 8 de febrero de 2011, en las que en base al principio de eficacia administrativa, al necesario control de un poder de persuasión o de decisión y en las consecuencias jurídicas de las actuaciones concretas, incluye dentro de la reserva funcional, actuaciones propias de controles de seguimiento o comprobación de cumplimiento, registro, el archivo y clasificación de documentos administrativos, tareas organizativas de los expedientes y de documentos, la tramitación de solicitudes con la fijación de su prelación y en su caso, su admisión, entre otros.

En suma, y como hemos podido comprobar, existen pues un amplio abanico de criterios que nos permiten orientarnos hacia dónde deberían caminar los legisladores

32 López Benítez, Mariano; Cantero Martínez, Josefa; Puerta Seguido, Francisco (2009): 154 y ss.

33 Por su parte, el capítulo IV del Título VII del TRRL (no derogado expresamente por el EBEP), establece en su art. 169 y ss., que corresponde a los funcionarios públicos el desempeño de funciones comunes al ejercicio de la actividad administrativa. En consecuencia, en este capítulo del TRRL, se establece que los puestos de trabajo predominantemente burocráticos habrán de ser desempeñados por funcionarios y en el que se detallan, asimismo, las concretas tareas a desempeñar por éstos.

Así, y también a título de ejemplo, se detallan las tareas de gestión, estudio y propuesta de carácter administrativo de nivel superior; las tareas de apoyo a las funciones de nivel superior; o, por poner un último ejemplo, las tareas administrativas, normalmente de trámite y colaboración. 
autonómicos tras el punto de inflexión marcado por el EBEP y la importancia que debería significar que en una normativa básica de función pública se recoja, por primera vez, una reserva funcional aunque sea a modo de límite mínimo a respetar por el conjunto de leyes autonómicas que sean aprobadas en desarrollo del EBEP. Veamos, pues, cuál es el criterio que se viene dibujando en el mapa autonómico.

\section{b) De la legislación en desarrollo del EBEP}

En primer lugar, hay que tener en cuenta que desde que se aprobó el EBEP (año 2007) y a pesar de las novedades que el nuevo texto básico de función pública incorpora sobre la materia, no son muchas las Comunidades Autónomas que se han decidido por actualizar sus respectivas leyes de función pública. Podríamos decir que estamos ante un proceso de reforma "a cuenta gotas", lógico en cierto modo si tenemos en cuenta la transcendencia de una reforma de este calado, y, más aun, considerando la filosofía de mínimo común denominador que el EBEP lleva aparejada y las amplias potestades que, con buena lógica, se abren para el resto de administraciones territoriales.

Dicho esto, y en cualquier modo, hay que poner de relieve también que este proceso de reforma lleva un ritmo desigual, como es lógico también, pero en algunos casos, en nuestra opinión, algo irracional. Así, si ojeamos el mapa autonómico, nos encontramos con Comunidades Autónomas que reformaron sus leyes de función pública durante la tramitación parlamentaria del EBEP (el caso de Baleares); otras las aprobaron a los pocos meses de la aprobación del EBEP y que, como no podía ser de otra manera, tuvieron que volver a actualizarse en poco menos de un año a modo de texto refundido (el caso de Galicia); también hay las que están actualizando sus leyes por "capítulos" (el caso de Asturias); las que recientemente han tomado la decisión de desarrollar y actualizar sus respectivas leyes de función pública en profundidad (el caso de Valencia y Castilla-La Mancha); y, finalmente, las que se encuentran en fase de borrador o de deliberación de las respectivas Comisiones de Expertos (el caso del resto de Comunidades Autónomas) ${ }^{34}$.

En este contexto, a continuación nos centraremos en algunos ejemplos de estas Comunidades Autónomas, especialmente en aquellas que a los efectos que aquí nos

34 Así nos encontramos, en primer lugar, con la Ley 3/2007, de 27 de marzo, de la Función Pública de la comunidad autónoma de las Illes Balears. En segundo lugar, la Ley 13/2007, de 27 de julio, de modificación de la Ley 4/1988, de 26 de mayo, de la función pública de Galicia; modificada posteriormente por el Decreto Legislativo 1/2008, de 13 de marzo, por el que se aprueba el texto refundido de la Ley de la función pública de Galicia. En tercer lugar, la Ley del Principado de Asturias 5/2009, de 29 de diciembre, de séptima modificación de la Ley del Principado de Asturias 3/1985, de 26 de diciembre, de ordenación de la Función Pública, para la regulación de la carrera horizontal; y, la Ley del Principado de Asturias 14/2010, de 28 de diciembre, de octava modificación de la Ley 3/1985, de 26 de diciembre, de Ordenación de la Función Públi-

166 ca. En cuarto lugar, la Ley 10/2010, de 9 de julio, de ordenación y gestión de la Función Pública Valenciana. Y, más recientemente, la Ley 4/2011, de 10 de marzo, del Empleo Público de Castilla-La Mancha. 
interesa, han abordado la reforma iniciada por el EBEP en nuestra legislación de función pública. Así, presentan especial interés en la materia que nos ocupa la legislación aprobada en Galicia, Valencia y Castilla-La Mancha, donde sus legisladores, con carácter general, aunque también algunos más que otros, han sabido estar a la altura de las circunstancias y las nuevas normas autonómicas, ahora sí, brillan por su claridad y concisión al menos en los contenidos que venimos abordando.

Desde esta perspectiva, pues, y siguiendo el esquema que venimos desarrollando, hay que destacar, en primer lugar, que estas leyes autonómicas, siguiendo la línea trazada por el EBEP, y con buena lógica también, incluyen dentro de su ámbito de aplicación a la entidades de derecho público vinculadas o dependientes de cualquiera de las Administraciones Públicas de las respectivas Comunidades Autónomas 35 .

En segundo lugar, por lo que respecta a las funciones que deben corresponder bien al personal funcionario o bien al personal laboral, el Decreto Legislativo 1/2008, de 13 de marzo, por el que se aprueba el texto refundido de la Ley de la función pública de Galicia, en su art. 27.2, establece que los puestos de trabajo de la Administración de la comunidad autónoma y de sus organismos autónomos de carácter administrativo "serán desempeñados por personal funcionario público".

No obstante, en términos muy similares al aun vigente art. 15.1 c) de la LMRFP, se exceptúan de la regla anterior y podrán ser desempeñados por personal laboral, los siguientes puestos de trabajo:

a) Los puestos de naturaleza no permanente y aquellos en los que sus actividades se dirijan a satisfacer necesidades de carácter periódico y discontinuo.

35 En el caso de Baleares, conforme a su art. 3, la Ley es de aplicación al personal al servicio de la Administración de la comunidad autónoma de las Illes Balears y de las entidades autónomas dependientes de la misma, con algunas limitaciones.

Por lo que respecta a las funciones del personal, su art. 14, establece que, con carácter general, los puestos de trabajo de la administración autonómica están reservados a personal funcionario de carrera. $Y$, en todo caso, los puestos de trabajo y las funciones cuyo cumplimiento implica ejercicio de autoridad, fe pública o asesoramiento legal, control y fiscalización interna de la gestión económico-financiera y presupuestaria, los de contabilidad y tesorería, los de carácter técnico y administrativo, los que comportan jefatura orgánica y, en general, los que se reservan a este personal para una mayor garantía de la objetividad, imparcialidad e independencia en el ejercicio de la función, así como los que implican una participación directa o indirecta en el ejercicio de la potestad pública y en la salvaguarda de los intereses generales de la comunidad autónoma. puestos:

El personal laboral (art. 17) únicamente puede llevar a cabo las funciones atribuidas a los siguientes

a) Los puestos cuyas actividades sean propias de una profesión determinada, que impliquen tareas de vigilancia, custodia, transporte u otras análogas, o que correspondan a áreas de actividades que requieran conocimientos técnicos, siempre y cuando estas funciones no sean las propias de cuerpos, escalas o especialidades de personal funcionario.

b) Los puestos correspondientes a las áreas de mantenimiento y de conservación de edificios, de equipos y de instalaciones.

c) Los puestos que la relación de puestos de trabajo reserva a personas con discapacidad intelectual moderada, ligera o límite y a las personas con sordera prelocutiva profunda, severa o media. 
b) Los puestos en los que sus actividades sean propias de oficios.

c) Los puestos correspondientes a áreas de actividades que requieran conocimientos técnicos especializados cuando no existan cuerpos o escalas de personal funcionario en los que las personas integrantes tengan la preparación específica necesaria para su desempeño.

d) Los puestos de carácter instrumental correspondientes a las áreas de mantenimiento y conservación de edificios, equipos e instalaciones, y artes gráficas, así como los puestos de las áreas de expresión artística.

e) Los puestos de trabajo de organismos autónomos de carácter comercial, industrial, financiero o análogo, excepto aquellos que impliquen ejercicio de la autoridad, inspección o control correspondiente a la consellería a la que estén adscritos, que se reservan al personal funcionario.

Por su parte, la Ley 10/2010, de 9 de julio, de ordenación y gestión de la Función Pública Valenciana, en su título III, partiendo del concepto de empleado público, categoría que engloba a todos cuantos desempeñan funciones retribuidas al servicio de los intereses generales en las administraciones públicas, contiene la regulación legal de las diferentes clases de personal. Subrayando, como garantía de los intereses públicos, la necesidad de que aquellos puestos de trabajo cuyo desempeño implique la participación directa o indirecta en el ejercicio de las potestades públicas o en la salvaguardia de los intereses generales deban ser desempeñados necesariamente por personal funcionario público.

Y especialmente destaca también aquí, el capítulo II de su título IV, que regula las relaciones de puestos de trabajo, siendo relevante, la introducción de la definición y concepto de puesto de trabajo, así como la sistematización y clarificación de los criterios en materia de clasificación de los mismos.

Concretamente, en su art. 15.3, establece que el personal funcionario de carrera desempeñará las "funciones que se atribuyen a los puestos clasificados con dicha naturaleza según el título IV de la presente ley y, en todo caso, y con carácter exclusivo, aquellas cuyo ejercicio implique la participación directa o indirecta en el ejercicio de las potestades públicas o en la salvaguardia de los intereses generales". Y, en su art. 37, establece que "con carácter general” los puestos de trabajo se clasificarán de naturaleza funcionarial.

Por lo que respecta al personal laboral, se deja bien claro que "únicamente podrá llevar a cabo las funciones que se atribuyen a los puestos clasificados con dicha naturaleza” y que, en ningún caso, "podrá ocupar puestos de trabajo clasificados para personal funcionario". El quebrantamiento de esta prohibición, como añade la norma valenciana en términos rotundos, "dará lugar a la nulidad del acto correspon168 diente, con la consiguiente responsabilidad de la persona causante del mismo" (art. 
17.4 y 5 de la Ley valenciana) $)^{36}$. Y, en esta línea, deja también bien claro que sólo podrán ser clasificados como puestos de naturaleza laboral aquellos que "impliquen el ejercicio de un oficio concreto" (art. 38 de la Ley valenciana).

En términos más clarificadores se expresa la Ley 4/2011, de 10 de marzo, del Empleo Público de Castilla-La Mancha. Así, en cumplimiento de la obligación prevista en el EBEP, se enuncian las funciones que, "como mínimo", quedan reservadas al personal funcionario por implicar la participación directa o indirecta en el ejercicio de las potestades públicas o en la salvaguardia de los intereses generales, a saber (art. 6 de la Ley de Castilla-La Mancha):

- La instrucción o la elaboración de propuestas de resolución en procedimientos administrativos.

- La inspección, vigilancia o control del cumplimiento de normas o resoluciones administrativas.

- La emanación de órdenes de policía.

- El control y fiscalización interna de la gestión económico-financiera y presupuestaria.

- La contabilidad.

- Las de tesorería.

- La fe pública.

- La recaudación.

- La inscripción, anotación, cancelación y demás actos de administración de registros públicos.

- El asesoramiento legal preceptivo.

36 Todo ello sin perjuicio de lo dispuesto en la disposición adicional segunda y transitoria quinta de esta ley relativos, la primera, a los "Procedimientos de regularización de la relación jurídica del personal laboral al servicio de la administración de la Generalitat" y, la segunda, al "Personal laboral fijo que desempeña funciones o puestos clasificados como propios de personal funcionario”. Ésta última señala que: “El personal laboral fijo que a la entrada en vigor de la presente ley esté desempeñando funciones propias del personal funcionario, o pase a desempeñarlas en virtud de pruebas de selección o promoción convocadas antes de dicha fecha, podrá seguir desempeñándolas.

Asimismo, podrá participar en los procedimientos selectivos de promoción interna convocados por el sistema de concurso oposición, de forma independiente o conjunta con los procedimientos selectivos de libre concurrencia, en aquellos cuerpos, agrupaciones profesionales funcionariales o escalas a los que figuren adscritos las funciones o los puestos que desempeñe, siempre que posea, en su caso, la titulación necesaria y reúna los restantes requisitos exigidos, valorándose a estos efectos como mérito los servicios efectivos prestados como personal laboral fijo y las pruebas selectivas superadas para acceder a esta condición". 
Pero, además, como nos aclara la norma, se pueden incluir en la relación de puestos de trabajo reservados al personal funcionario puestos de trabajo que tengan asignadas funciones distintas a las anteriores. Dejando sentado, a su vez, que las funciones instrumentales, auxiliares o de apoyo "no participan en el ejercicio de las potestades públicas o en la salvaguardia de los intereses generales". Desde esta perspectiva, como establece en su art. 11, el personal laboral únicamente puede desempeñar los siguientes empleos:

a) Los empleos de naturaleza no permanente y aquellos cuyas actividades se dirijan a satisfacer necesidades de carácter periódico y discontinuo.

b) Los empleos cuyas actividades sean propias de oficios, así como los que conlleven tareas de vigilancia, recepción, información, custodia, porteo, reproducción de documentos, conducción de vehículos y otros análogos.

c) Los empleos de carácter instrumental correspondientes a las áreas de mantenimiento y conservación de edificios, equipos, instalaciones o vías públicas.

d) Los empleos correspondientes a áreas de actividades que requieran conocimientos técnicos especializados cuando no existan cuerpos de personal funcionario cuyos miembros tengan la preparación específica necesaria para su desempeño.

e) Los empleos que se reserven de forma exclusiva a las personas que accedan por el sistema específico de acceso de personas con discapacidad.

En ningún caso, como deja también bien claro el citado artículo de la Ley de Castilla-La Mancha, se podrá contratar personal laboral para el ejercicio de funciones reservadas al personal funcionario ${ }^{37}$.

En suma, dejamos, pues, constancia nuevamente de cuáles son los parámetros que podemos encontrar en la normativa actual, en este caso de la legislación autonómica en desarrollo del EBEP, que nos permiten clarificar un poco más cuáles son los criterios a tener en cuenta en esta ardua tarea de delimitación de funciones entre el personal funcionario y el personal laboral de nuestras Administraciones Públicas. Concepto éste último que, como ha quedado apuntado y así se corrobora en la nor-

37 Excepto en los siguientes casos y siempre que no impliquen la participación directa o indirecta en el ejercicio de las potestades públicas o en la salvaguardia de los intereses generales (art. 11.4 de la Ley de Castilla-La Mancha):

a) Contratos de trabajo en prácticas o para la realización de una obra o servicio determinados, siempre que dichas contrataciones se realicen en virtud de convocatorias de ayudas o subvenciones de Administraciones públicas o de la Unión Europea que exijan dichas modalidades contractuales, y que, en todo caso, finalicen cuando así lo establezca la normativa aplicable.

b) Contratos de trabajo con el personal investigador en los términos previstos en la normativa so-

170 bre investigación científica y técnica. 
mativa de función pública vigente, se extiende también al personal que, con independencia de su vínculo jurídico, presta sus servicios en el conjunto de entidades de derecho público vinculadas o dependientes de ellas.

\section{CONSIDERACIONES FINALES}

Como ha quedado demostrado a lo largo de este trabajo, podemos afirmar que contamos con unos criterios legales que con el paso del tiempo, y a medida que salen a la luz nuevas normas de función pública, se van perfilando más y más.

Son múltiples, pues, los criterios a tener en cuenta en la integración de este personal y las funciones por ellos a desarrollar: De los parámetros comunitarios y su recepción en el EBEP; de la normativa anterior a éste y que sigue en vigor; de la reciente legislación autonómicas en desarrollo del EBEP. Todos apuntan en una misma dirección.

Que la regla general no puede ser la ocupación de estos puestos de trabajo por personal laboral. Que los funcionarios públicos no sólo les corresponde en exclusiva el desarrollo de funciones que impliquen la participación directa o indirecta en el ejercicio de las potestades públicas o en la salvaguarda de los intereses generales del Estado y de las Administraciones Publicas. Que la delimitación de funciones del personal de estas agencias no puede ser "al gusto del consumidor". Que no es indiferente asignar cualquier puesto de trabajo a personal de uno u otro tipo.

Por nuestra parte, quede aquí apuntado estos lineamientos básicos sobre las funciones que deben asumir estos trabajadores del sector público de las nuevas agencias andaluzas. Nada parecido, como hemos podido comprobar, con los términos utilizados por el legislador andaluz en su nueva Ley $1 / 2011$. Por lo que no estaría nada mal que tomasen buena nota al respecto, toda vez que queda pendiente también que la Junta de Andalucía se decida por aprobar su respectiva norma de función pública en desarrollo del EBEP.

Precisamente por ello, es preciso tener muy presente, como dejó apuntado el Informe de la Comisión de Expertos, que: "en muchas Administraciones coexiste el personal funcionario y el laboral desempeñando puestos de trabajo de similar naturaleza, pero bajo un régimen jurídico distinto y ello crea diferencias injustificadas y agravios, al tiempo que perjudica la gestión eficaz de los recursos humanos. La resolución de este problema debe basarse en una "regla de oro" elemental, esto es, establecer, en la medida de lo posible, un solo régimen jurídico para los empleados que realizan cada tipo de función pública. Esta premisa obliga al legislador a definir con precisión qué funciones corresponden al personal funcionario y cuáles otras al personal laboral"38.

$38 \operatorname{MAP}(2005): 48$

De otro lado, como deja apuntado Jiménez Asensio (2008): 7: «Aquí, el legislador deberá ser muy receptivo a la realidad actual del mundo local y, en consecuencia, abrir lo máximo posible la posibilidad de 
$\mathrm{Y}$, desde esta perspectiva, ha de reiterarse también que, como en otros supuestos del sistema de gestión de recursos humanos, muchos de los problemas existentes radican, más que en el acierto y la perfección técnica de las normas que lo regulan que resulta obvio que también, en la correcta aplicación de las mismas. $\mathrm{Y}$, simplemente, superar las patologías ya conocidas supondría un gran salto adelante en esta materia.

Quiere decirse, siguiendo las reflexiones de Castillo Blanco referidas al ámbito local pero que son perfectamente extrapolables aquí, que: "acometer una reforma en este punto pasa por un cambio en la cultura de su aplicación y por tener, de forma previa a la ejecución de los distintos mecanismos previstos para su aplicación, un buen análisis de los puestos de trabajo, huyendo de automatismos y análisis estandarizados donde la singularidad así lo exija, y de los requisitos, habilidades competencias y destrezas que requiere el ejercicio de los mismos".

Esta actuación, simplemente y en sí misma, abre un amplio espectro de posibilidades de acción en las nuevas agencias andaluzas. Por ello, atendiendo a la perspectiva que subyace en el EBEP y en las nuevas normas autonómicas en desarrollo de éste, se debería emprender, como señala el autor, "un buen estudio organizativo -no ligado exclusivamente a la estructuración política de la entidad y condicionado por ésta (me refiero, en concreto, en la creación de áreas organizativas en base al establecimiento de delegaciones políticas)-, base de la futura organización administrativa plasmada en la relación de puestos de trabajo o instrumento similar, que indique, para atender a las competencias y a los servicios que se prestan o han de prestarse, los puestos de trabajo, singularizados o no, necesarios y muy especialmente para los primeros el perfil profesional de desempeño necesario"39.

Y, quede claro también, no obstante, y a la vista de los criterios delimitadores que la normativa y la jurisprudencia nos ofrece, que hay que tener siempre muy presente que en la eventual impugnación de unos puestos de trabajo por considerar que son propios de la categoría de funcionarios (o viceversa), se debe realizar una comparación, caso por caso y no de forma general, a efectos de poder determinar el elemento comparativo entre ambos puestos de trabajo y, de ese modo, permitir llegar a la determinación de qué clase de personal es el que debería ocupar el puesto de trabajo que se cuestiona.

que las administraciones públicas puedan contratar personal laboral para el desempeño de determinadas funciones, lo que no implica una apuesta por un modelo de laboralización intensiva, sino por un modelo flexible que cada administración pública adaptará a sus necesidades. Esta opción, sin embargo, puede dificultar -y hay que ser consciente de ello- una apuesta por la construcción de un modelo de empleo público a nivel autonómico asentado sobre bases homogéneas y en el que se fomente la movilidad interadministrativa. Tal vez la solución a estos hipotéticos problemas vayan en la línea de impulsar la creación de puestos de trabajo «polivalentes», esto es, que puedan ser desempeñados indistintamente por personal funcionario o personal laboral. Esto es perfectamente posible en aquellos casos en que no haya reserva de funciones a funcionarios públicos y que puedan cubrirse tales puestos de trabajo -según lo que determine

172 el legislador autonómico- por personal laboral». 


\section{BIBLIOGRAFÍA}

AA.VV. (2007): Comentarios a la Ley del Estatuto Básico del Empleado Público, Valladolid, Ed. Lex Nova.

AA.VV. (2007): Estatuto Básico del Empleado Público, Madrid, Ed. La Ley-El Consultor.

AA.VV. (2007): El Estatuto Básico del empleado público y su incidencia en el ámbito local, Granada, Ed. CEMCI.

AA.VV. (2008): Comentarios a la Ley 7/2007, del Estatuto Básico del Empleado Público, Pamplona, Ed. Aranzadi.

AA.VV. (2008): El Estatuto Básico del Empleado Público. Comentario Sistemático a la Ley 7/2007, de 12 de abril, de 2007, Granada, Ed. Comares.

AA.VV. (2008): El Estatuto Básico del Empleado Público. Propuestas de desarrollo legislativo por parte de las Comunidades Autónomas, Barcelona, Ed. CEMICAL.

AA.VV. (2009): Manual de Empleo Público, Madrid, Ed. IUSTEL.

Jiménez Asensio, Rafael (2008): “Clases de personal”, El Estatuto Básico del Empleado Público. Propuestas de desarrollo legislativo por parte de las comunidades autónomas, Ed. CEMICAL, Barcelona, págs. 15-18.

Jiménez Asensio, Rafael; Castillo Blanco, Federico (2009): Informe sobre el empleo público local. Balance y propuestas para su racionalización en el marco de la reforma del empleo público, Madrid, Ed. Fundación Democracia y Gobierno Local.

López Benítez, Mariano; Cantero Martínez, Josefa; Puerta Seguido, Francisco (2009): "Estructura de empleo público y clases de empleados públicos", Manual de Empleo Público, Madrid, Ed. lustel, , págs. 89 y 196.

MAP (2005): Informe de la Comisión para el estudio y preparación del Estatuto Básico del Empleado Público, Madrid, Ed. INAP.

Rebollo Puig, Manuel (2003): “Los entes institucionales de la Junta de Andalucía y su utilización como medio propio”, Revista de Administración Pública, № 161, págs. 359-393.

Sánchez Morón, Miguel (2007a): “Objeto y ámbito de aplicación”, Comentarios a la Ley del Estatuto Básico del Empleado Público, Valladolid, Ed. Lex Nova, págs. 4381.

Sánchez Morón, Miguel (2007b): “Clases de personal”, Comentarios a la Ley del Estatuto Básico del Empleado Público, Ed. Lex Nova, Valladolid, págs. 83-113. 